\title{
QUIIMICA MINERAL DAS ROCHAS VULCÂNICAS DA PENÍNSULA FILDES (ILHA REI GEORGE), ANTÁRTICA
}

\section{ADRIANE MACHADO ${ }^{1}$, EVANDRO FERNANDES DE LIMA ${ }^{2}$, FARID CHEMALE JR. ${ }^{2}$, JOAQUIM DANIEL DE LIZ $^{3}$ \& JANAÍNA NUNES ÁVILA ${ }^{3}$}

\begin{abstract}
MINERAL CHEMISTRY OF VOLCANIC ROCKS FROM FILDES PENINSULA (KING GEORGE ISLAND), ANTARTIC Studies realized in the Fildes Peninsula (southwest King George Island, Antartic) permited the identification of volcanic rocks succession from basic to intermediate composition. Dacites and rhyolites are rare. The age of these rocks vary from Paleocene to Eocene. Geochemistry studies indicate these rocks are rich in $\mathrm{Al}_{2} \mathrm{O}_{3}, \mathrm{Rb}, \mathrm{Ba}, \mathrm{Sr}$ and they present enrichment in $\mathrm{LREE}$ relative to HREE. It is typical of high-Al volcanic association with calc-alkaline affinity. It is evinced for Alkali Index x Al, $\mathrm{O}_{3}$ diagram. The $\mathrm{Ni}, \mathrm{Cr}, \mathrm{Co}, \mathrm{MgO}$ contents of basic rocks are lower than primary compositions and it discloses that these magmas are evolved. ${ }^{87} \mathrm{Sr} /{ }^{86} \mathrm{Sr}$ initial ratios are 0.7033 to 0.7037 and ${ }^{143} \mathrm{Nd} /{ }^{144} \mathrm{Nd}$ are 0.512959 to 0.512967 . The values of $\mathrm{eNd}(\mathrm{t}=55 \mathrm{Ma})$ range between +6.52 and +6.72 . The Isotopic and Geochemistry data suggest that the rocks were generated from partial melting of lithospheric mantle in an island arc environment. Fildes Peninsula volcanic rocks present porphyritic, glomeroporphyritic, intergranular and intersertal textures. Mineral chemistry indicates typical compositon of low-K and calc-alkaline series of island arcs. Plagioclase compositions are mostly anorthite and bytownite in the basic rocks and mostly bytownite in the intermediate

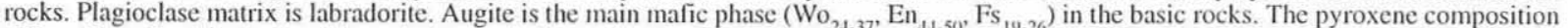
$\left(\mathrm{Wo}_{38}, \mathrm{En}_{45}, \mathrm{Fs}_{17}\right)$ in the basaltic andesites is similar to basalts. Pigeonite $\left(\mathrm{WO}_{0}^{37}, \mathrm{En}_{15}, \mathrm{En}_{52.67}, \mathrm{Fs}_{23.33}\right)$ is unusual phase and it is only presents in the matrix of basalts. Bronzite $\left(\mathrm{Wo}_{3 . f}, \mathrm{En}_{70}, \mathrm{Fs}_{26_{2} 27}\right)$ occurs as microphenocryst in two samples of basaltic andesites. Olivine is common phase in the basic rocks and it shwos crisolite composition. The opaque phase is represented for magnetite. It contains ulvospinel from 16 to $25 \%$. Geothermobarometry of clinopyroxene-orthopyroxene from basaltic andesite (AF-2I) was obtained by Ca-QUILF Program. It yielded a crystallization and equilibration temperature between $1065^{\circ} \mathrm{C}$ to $1070^{\circ} \mathrm{C}$ for pressures from I bar to 1500 bar. The evaluation of Mincral Chemistry, Lithochemistry and Isotopic compostions are according to hypothesis of fractional crystallization for evolution of Fildes Peninsula volcanic rocks. It was not found evidences for interference of other petrogenetic processes.
\end{abstract}

Keywords: basalts, mineralogy, Antartic

RESUMO Estudos realizados na Península Fildes, sudoeste da llha Rei George (Arquipélago Shetand do Sul, Antártica), permitem a identificação de uma sucessão de rochas vulcânicas básicas a intermediárias, além de raros dacitos e riolitos, de idades paleocênica a eocênica. A geoquímica destas rochas indica conteúdos elevados de $\mathrm{Al}, \mathrm{O}, \mathrm{Rb}, \mathrm{Ba}, \mathrm{Sr}$ e um leve enriquecimento em ETRLs em relação a ETRPs, típicos de uma associação vulcânica de alto-alumínio de afinidade cálcico-alcalina. Entre os diagramas que discriminam séries magmáticas, a do Índice de Alcalinidade versus $\mathrm{Al}_{2} \mathrm{O}_{3}$ é o que melhor determina a condiçâo célcico-alcalina destes vulcanitos. Os conteúdos de $\mathrm{Ni}$. $\mathrm{Cr}, \mathrm{Co}$ e $\mathrm{MgO}$ das rochas básicas são inferiỡes àqueles encontrados em composições primaírias e atestam a condição evolúda destes magmas. Os dados isotópicos obtidos em rochas básicas indicam razões iniciais de ${ }^{87} \mathrm{Sr} /{ }^{\prime 66} \mathrm{Sr}$ de 0,7033 a $0,7037 \mathrm{e} \mathrm{de}{ }^{1+3} \mathrm{Nd} / 144 \mathrm{Nd}$ de $0,512959 \mathrm{e} 0,512967$. Os valores de eNd para $\mathrm{t}=55 \mathrm{Ma}$ (idade modelo) é de $+6,52 \mathrm{e}+6,72$. A assinatura isolópica e os dados geoquímicos sugerem que os vulcanitos foram gerados a partir da fusão parcial do manto litosférico em um ambiente de arco de ilhas. As rochas vulcânicas da Península Fildes possuem texturas porfirítica, glomeroporfirítica, intergranular e intersertal. Dados de química mineral indicam composições típicas das séries baixo$\mathrm{K}$ e cálcico-alcalinas de arco de ilhas. As séries de diferentes populaçōes de fenocristais de plagioclásio variam de anortita a bytownita nos termos básicos e são dominantemente bytownita nas rochas intermediárias. Na matriz dos vulcanitos o plagioclásio é do tipo labradorita. A augita é a fase máfica principal e varia de $\mathrm{Wo}_{2+37}, \mathrm{En}_{4+.50}, \mathrm{Fs}_{19.26}$ nos termos básicose de $\mathrm{Wo}_{38}, \mathrm{En}_{45}, \mathrm{Fs}_{17}$ nos andesitos basálticos. Pigconita (Wo ${ }_{15}, \mathrm{En}_{52-67}, \mathrm{Fs}_{23,33}$ ) é uma fase rara e restrita à matriz dos básaltos. Bronzita $\left(\mathrm{IVo}_{3.4}, \mathrm{En}_{30}, \mathrm{Fs}_{26.27}\right.$ ) é identificada como microfenocristal em duas amostras de andésesitos basálticos. A olivina é uma fase comum nos termos básicos é está geralinente alterada, com dados obtidos em um diabásio indicando uma composição do tipo crisolita. A fase opaca identificada é magnetita com uma concentração de ulvoespinélio da ordem de $16 \%$ a 25\%. Dados de química mineral do par clinopiroxênio-ortopiroxênio do andesito basáltico (AF-21) utilizados no programa Ca-QUILF sugerem uma temperatura de cristalização e um equilíbrio destas fases dentro do intervalo de $1065^{\circ} \mathrm{C}-1070^{\circ} \mathrm{C}$ para pressōes da ordem de 1 bar a 1500 bar. A investigação dos dados de química mineral, litoquímica e isotópicos são coerentes com a hipótese de cristalização fracionada para evolução dos vulcanitos da Península Fildes, não sendo encontradas evidências que sugerissem a interferência de outros fatores petrogenéticos.

Palavras-chaves: basaltos, mineralogia, Antártica

INTRODUÇÃo O Arquipélago Shetland do Sul (Antártica) constitui uma estrutura arqueada com cerca de $550 \mathrm{~km}$ de comprimento onde ilhas e blocos continentais submersos distribuem-se desde o extremo sul da América do Sul até a Península Antártica. Evidências geofísicas sugerem que estas ilhas estão localizadas em uma pequena placa crustal e podem ser divididas em duas partes geografica e geologicamente distintas (Tyrrell 1945): o grupo de ilhas Elefante e Clarence, constituídas por rochas metamórficas de baixo grau e pelas ilhas distribuídas entre Rei George e Low, formadas por rochas ígneas e vulcanoclásticas que são separadas do primeiro grupo por uma distância de 120 km. A Península Fildes (Fig. 1) situa-se no sudoeste da Ilha Rei George e é constituída por uma sucessão de rochas vulcânicas paleocênicas a eocênicas com intercalações de vulcanoclásticas de granulometria grossa a fina. A origem destes vulcanitos está vinculada a subducção da placa Antártica sob a placa de Aluke ao redor do limite Cretáceo-Terciário (Barker 1970 , Barker \& Griffiths 1972).

As rochas vulcânicas são representadas por basaltos e andesitos basálticos, além de raros andesitos, dacitos e riolitos. As rochas vulcanoclásticas são definidas como brechas vulcânicas, aglomerados, conglomerados vulcânicos, tufos e arenitos tufáceos. Plugs e diques de composição básica a ácida cortam as rochas vulcânicas e vulcanoclásticas. Cones vulcânicos parcialmente dissecados, enxames de diques radiais e anelares, em geral hidrotermalmente alterados, também ocorrem.

O presente trabalho apresenta resultados de química mineral obtidos a partir de uma campanha de amostragem realizada no verão de 1995. Inserem-se em um projeto mais amplo de investigação de rochas vulcânicas, que incluem as ilhas Rei George, Nelson, Robert, Greenwich e Livingston.

O objetivo do presente trabalho é apresentar e discutir resultados de química mineral c litoquímica das rochas vulcânicas básicas e intermediárias da Península Fildes para propor a origem e evolução dos vulcanitos.

METODOS ANALíticos Os dados de química mineral em plagioclásio, piroxênio, olivina e minerais opacos, obtidos em 11 amostras (295 pontos analisados) no Laboratório de Microssonda Eletrônica da Universidade Federal do Rio Grande do Sul-UFRGS, utili-

I - Programa de Pós-Graduação em Geociências, Universidade Federal do Rio Grande do Sul-UFRGS, Av. Bento Gonçalves, 9500, Campus do Vale, Prédio 43113, Bloco 1, Sala 207, Agronomia, 91501-970, Porto Alegre, RS, e-mail: adrianemachado@yahoo.com.br

2 - Instituto de Geociências, Universidade Federal do Rio Grande do Sul-UFRGS, Av. Bento Gonçalves, 9500, Campus do Vale, Agronomia, 91501-970, Porto Alegre, RS, e-mails: evandro@if.ufrgs.br; chemale@if.ufrgs.br

3. Bolsista de Iniciação Científica CNPq, Instituto de Geociências. Universidade Federal do Rio Grande do Sul-UFRGS, Av. Bento Gonçalves, 9500 , Campus do Vale, 91501-970, Porto Alegre, RS, e-mails: javila@if.ufrgs.br: danielliz@ hotmail.com 


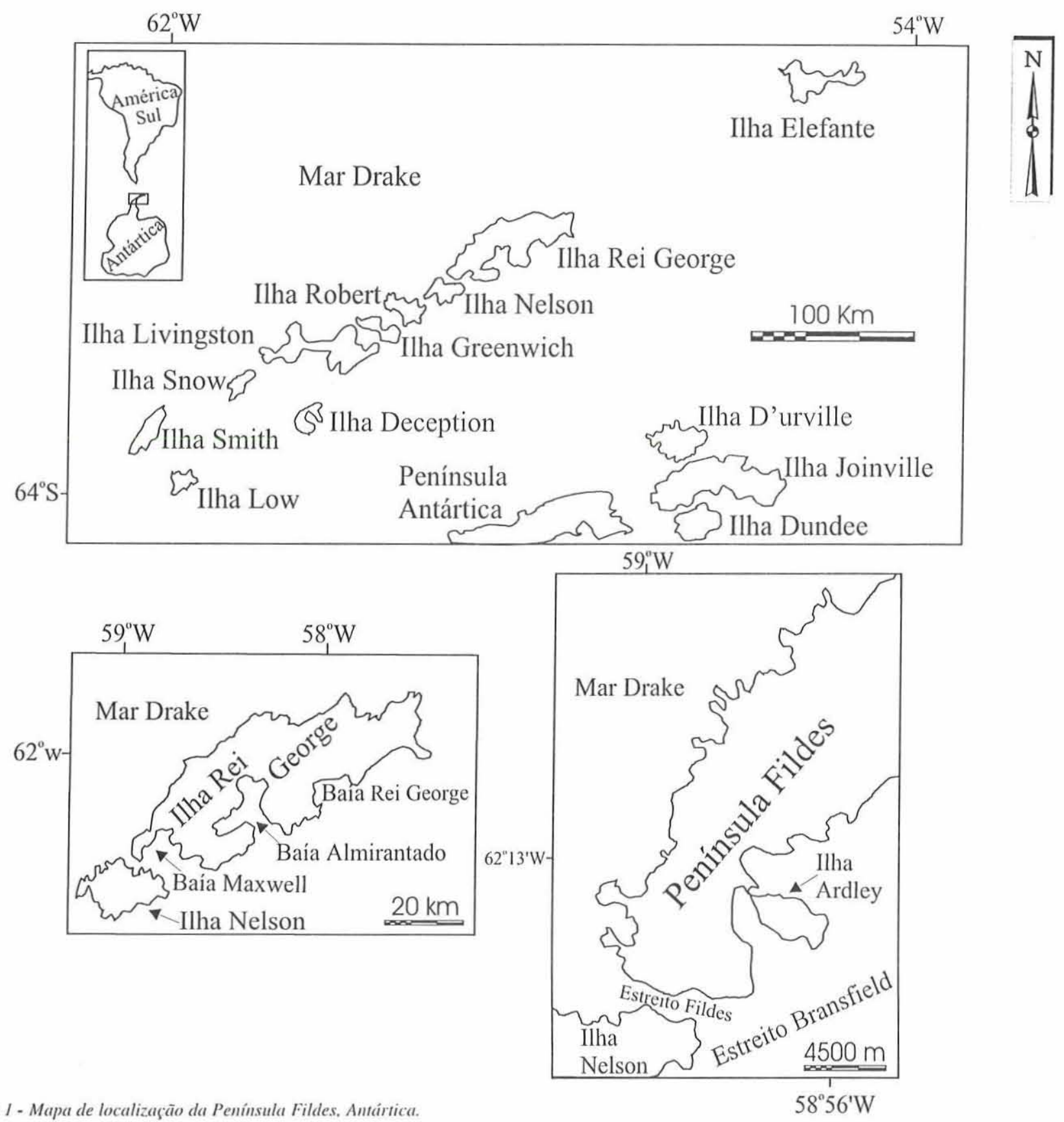

Figura I - Mapa de localizașão da Península Fildes. Antártica.

s); Fe (20 s); Mg (30 s); Mn (30 s); Ca (40 s); Ni (40 s); Cr (40 s).

As análises químicas de rocha total de elementos maiores, traço e quatro espectômetros WDS verticais c um EDS kevex. A correção fo do tipo PAP. Os padrões químicos utilizados para a calibragem foram: $\mathrm{Si}$ - Anor; $\mathrm{Ti}-\mathrm{TiO}_{2} ; \mathrm{Al}$ - Anor; $\mathrm{Fe}-\mathrm{MnHO} ; \mathrm{Mg}-\mathrm{MnHO} ; \mathrm{Mn}$ $\mathrm{MnHO}$; $\mathrm{Ca}$ - Anor; $\mathrm{Na}$ - Jade; $\mathrm{K}$ - Asbe; $\mathrm{Ni}-\mathrm{NiO} ; \mathrm{Cr}-\mathrm{Cr}$, O. A tensão de aceleração, a corrente, o diâmetro do feixe e os tempos de contagem de pontos (cada elemento químico) estão abaixo descritos para cada mineral, respectivamente:

Plagioclásio: 15 kV; $10 \mathrm{nA} ; 5 \mu \mathrm{m} ; \mathrm{Si}(30 \mathrm{~s}) ; \mathrm{Al}(20 \mathrm{~s}) ; \mathrm{Fe}(60 \mathrm{~s})$; $\mathrm{Mg}(30 \mathrm{~s}) ; \mathrm{Ca}(30 \mathrm{~s}) ; \mathrm{Na}(30 \mathrm{~s}) ; \mathrm{K}(30 \mathrm{~s}) ;$

Piroxênio: $15 \mathrm{kV} ; 10 \mathrm{nA} ; 1 \mu \mathrm{m}$; $\mathrm{Si}(30 \mathrm{~s})$; Ti (30 s); $\mathrm{Al}(25 \mathrm{~s}) ; \mathrm{Fe}$ (20 s); Mg (25 s); Mn (30 s); Ca (25 s); Na (30 s); K (25 s); Cr (30 s); Olivina: $15 \mathrm{kV} ; 10 \mathrm{nA} ; 1 \mu \mathrm{m}$; $\mathrm{Si}(40 \mathrm{~s}) ; \mathrm{Ti}(20 \mathrm{~s}) ; \mathrm{Al}(40 \mathrm{~s}) ; \mathrm{Fe}(20$ s); $\mathrm{Mg}(20 \mathrm{~s}) ; \mathrm{Mn}(20 \mathrm{~s}) ; \mathrm{Ca}(30 \mathrm{~s}) ; \mathrm{Na}(30 \mathrm{~s}) ; \mathrm{Ni}(30 \mathrm{~s}) ; \mathrm{Cr}(40 \mathrm{~s})$;

Minerais opacos: $15 \mathrm{kV} ; 25 \mathrm{nA} ; 1 \mu \mathrm{m} ; \mathrm{Si}(50 \mathrm{~s})$; Ti (20 s); Al (30 terras raras foram realizadas no Laboratório de Fluorescência de Raios$X$ da Universidade Federal do Rio Grande do Sul-UFRGS, no Instituto de Pesquisas Energéticas e Nucleares - São Paulo (ativação neutrônica), segundo o método de Figueiredo \& Marques (1989) e no Activation Laboratories LTD (ACTLABS), Canadá, utilizando-se a técnica de espectrometria de plasma de argônio (ICP).

Os minerais de argila foram inicialmente identificados por métodos óticos convencionais e, posteriormente, realizou-se o método difratométrico qualitativo do pó (câmara de Debye Sherrer) no difratômetro de Raios-X da Universidade Federal do Rio Grande do Sul.

Os cálculos geotermométricos foram realizados por meio do programa Ca-QUILF (Piroxênio cálcico-Quartzo-Ulvoespinélio-Ilmenita- 
Fayalita) de Frost \& Lindsley (1992), cujas considerações teóricas constam em Lindsley \& Frost (1992).

Os dados analíticos de $\mathrm{Sm}-\mathrm{Nd}$ e Rb-Sr foram obtidos no Laboratório de Geoquímica Isotópica da Universidade de Kansas (E.U.A.). As composições isotópicas foram medidas com um espectrômetro de massa VG-Sector de cinco coletores. O Rb e Sm foram depositados em filamentos de Ta e analisados no modo coletor simples ou multicoletores estáticos. $\mathrm{O} \mathrm{Nd} \mathrm{e} \mathrm{Sr}$ foram depositados em filamentos de Re e analisados no modo dinâmico.

PETROGRAFIA As rochas vulcânicas são classificadas segundo Le Bas et al. (1986), que estabelecem que os basaltos possuem menos de $52 \%$ de $\mathrm{SiO}_{2}$ e os andesitos basálticos possuem entre 52 e $56 \%$.

Os basaltos e andesitos basálticos possuem textura porfirítica, glomeroporfirítica, intergranular e intersertal. Os fenocristais são dominantemente de plagioclásio, tabulares, maclados ou zonados, aliados a microfenocristais de clinopiroxênio e minerais opacos, localmente estando a olivina parcial ou totalmente alterada. O ortopiroxênio ocorre como microfenocristal e é identificado em apenas duas amostras de andesito basáltico. A matriz é constituída por microcristais e micrólitos de plagioclásio, piroxênio e minerais opacos. O resíduo de cristalização é constituído por vidro vulcânico e por uma alteração verde-amarelada a amarelo-esverdeada classificada, por difração de Raios-X, como argilo-minerais do grupo da esmectita. Algumas amostras contém vesículas e amígdalas preenchidas por quartzo e/ou argilo-minerais (esmectita), além de microveios de carbonato. A textura glomeroporfirítica é caracterizada pelo agrupamento de fenocristais de plagioclásio, por vezes acompanhados de piroxênio e minerais opacos.

LITOQUímICA Para o estudo litoquímico foram selecionadas amostras com os menores conteúdos de perda ao fogo e desprovidas de amígdalas e vesículas. As rochas vulcânicas da Península Fildes possuem baixos teores de $\mathrm{MgO}, \mathrm{Co}, \mathrm{Ni}$ e $\mathrm{Cr}$ (Tabela 1), típicos de magmas evoluídos. $\mathrm{O} \mathrm{Al}_{2} \mathrm{O}_{3}, \mathrm{Rb}, \mathrm{Ba}, \mathrm{Sr}$ apresentam concentrações elevadas acompanhadas de um empobrecimento relativo em elementos do tipo HFS (Fig. 2) e um leve enriquecimento em elementos terras raras leves em relação aos elementos terras raras pesados (Fig.3), sendo estas características comuns em rochas de afinidade cálcio-alcalina geradas em ambientes orogênicos.

Um moderado enriquecimento em $\mathrm{FeO}^{\mathrm{T}}$ é observado com a diferenciação, fato este normalmente correlacionado as rochas toleíticas. Entretanto a afinidade geoquímica não é claramente sugerida tanto no diagrama do tipo $\mathrm{FeO}^{\mathrm{T}} / \mathrm{MgO}$ versus $\mathrm{SiO}_{2}$ (Fig.4A) como no AFM (Fig.4B), onde as amostras distribuem-se em diferentes campos. Estes padrōes geoquímicos contrastantes determinaram diferentes interpretações para os vulcanitos da região, i) Hawkes (1961) classificou estas rochas como cálcio-alcalinas; ii) Smellie et al. (1984) afirmaram que os andesitos são cálcio-alcalinos e os termos básicos toleíticos; iii) Zheng et al. (1988) colocam estas rochas como pertencentes, basicamente, à série cálcio-alcalina, mas com algumas feições de toleítos de arco de ilhas.

Esta aparente ambigüidade nos trend do ferro em relação ao comportamento de alguns elementos maiores e traços das rochas vulcânicas da Península Fildes é também observada em outros arcos de illas,
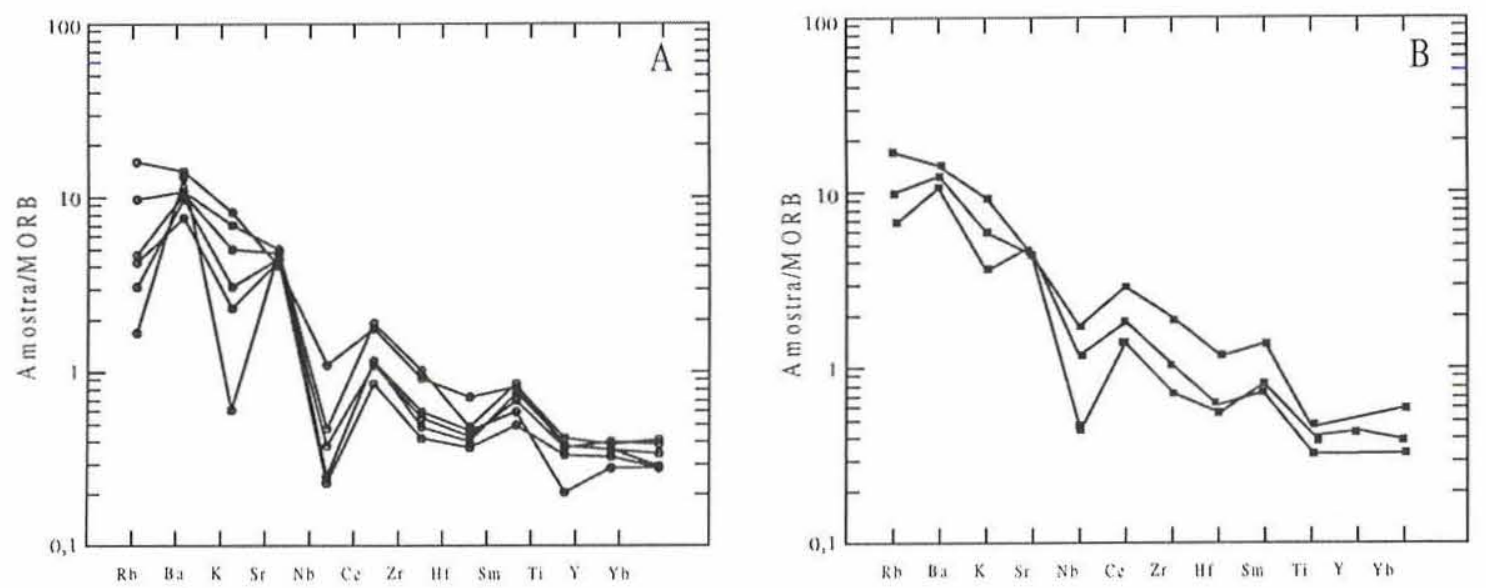

Figura 2 - Diagrama multi-elementar das rochas básicas (A) e intermediárias (B) da Península Fildes normalizado pelo padrão do basalto de cordilheira mesoocênica (MORB) de Pearce (1982). 

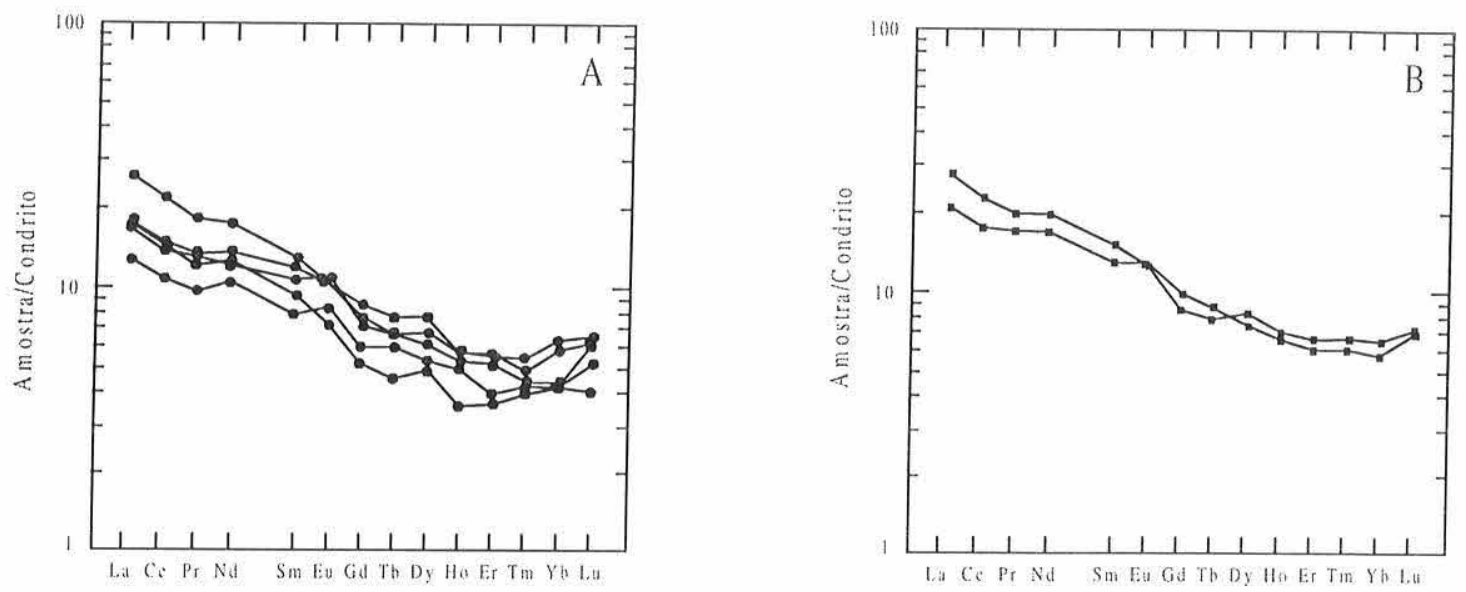

Figura 3 - Padrões de elementos terras raras das rochas básicas (A) e intermediárias (B) da Península Fildes normalizados pelos valores condríticos de Nakamura (1974).
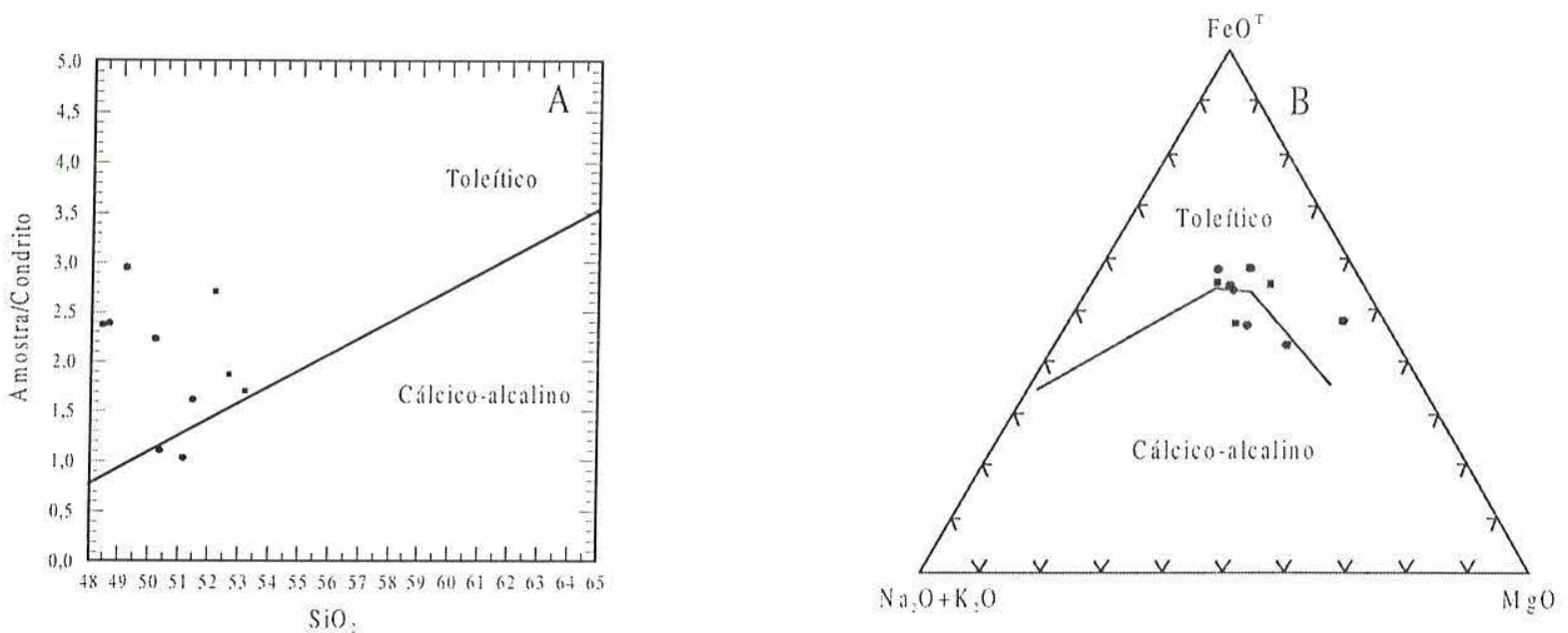

Figura 4 - (A) Diagrama de correlą̧ão $\mathrm{SiO}_{2}$ versus $\mathrm{FeO}{ }^{T} \mathrm{MgO}$ das rochas básicas e intermediárias da Península Fildes. (B) Distribuição da composição das rochas valcânicas básicas e intermediárias da Península Fildes no diagrama $\mathrm{FeO}^{\mathrm{T}}-\mathrm{MgO}_{\mathrm{g}}-\mathrm{Na}_{2} \mathrm{O}+\mathrm{K}_{2} \mathrm{O}$.

Os resultados obtidos no presente trabalho confirmam que os vulcanitos da Península Fildes, no que se refere a elementos do tipo litófilos de grande raio iônico (LIL), HFS e terras raras leves (ETRL), além de $\mathrm{Al}_{2} \mathrm{O}_{3}$, possuem uma afinidade cálcio-alcalina.

Testes de balanço de massa e com elementos-traço realizados por Machado et al. (1998) permitem explicar a origem das rochas intermediárias a partir da cristalização fracionada de olivina+clinopiroxênio+ plagioclásio a partir de líquidos básicos evoluídos com alto-alumínio.

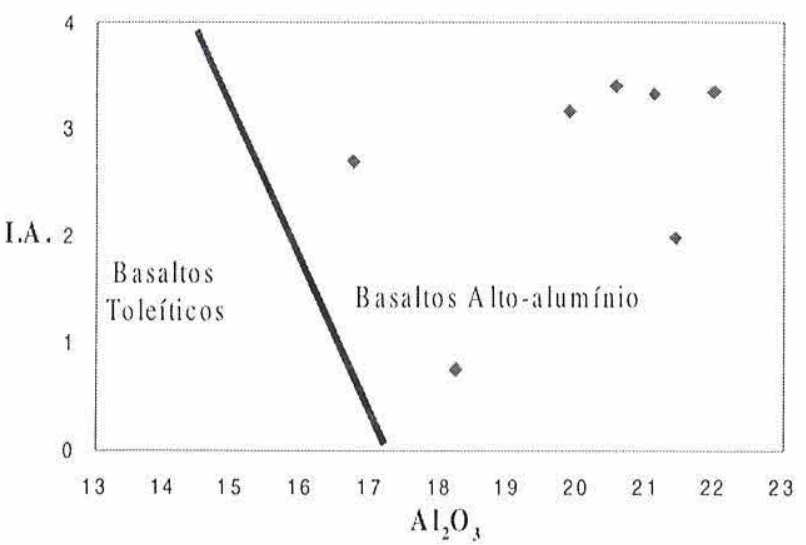

Figura 5- Diagrama de Índice de Alcalinidade $\left(\left(\mathrm{Na}_{2} \mathrm{O}+\mathrm{K}_{2} \mathrm{O} / \mathrm{SiO}_{2}-43\right) x\right.$ $0.17)$ versus $\mathrm{Al}_{2} \mathrm{O}_{3}$ (\% peso) para a classificaşäo de basaltos toleíiticos e cálcio-alcalinos de alto-alumínio.
Os dados isotópicos obtidos em rochas básicas indicam razões iniciais de ${ }^{87} \mathrm{Sr} /{ }^{86} \mathrm{Sr}$ de 0,7033 a $0,7037 \mathrm{e}$ de ${ }^{143} \mathrm{Nd} /{ }^{144} \mathrm{Nd}$ de 0,512959 e 0,512967 . Os valores de $\varepsilon N d$ para $\mathrm{t}=55 \mathrm{Ma}$ (idade modelo) é de + $6,52 \mathrm{e}+6,72$. Os resultados obtidos são semelhantes aos apresentados por Smellie et al. (1984), Li \& Liu (1987) e Jin et al. (1991). A assinatura isotópica, a petrografia e os dados geoquímicos sugerem que as rochas foram geradas por um processo de cristalização fracionada, a partir da fusão parcial do manto litosférico $\mathrm{em}$ um ambiente de arco de ilhas.

QUÍMICA MINERAL A composição química e variações de cada fase mineral que compõe as rochas vulcânicas básicas e intermediárias da Península Fildes são aqui apresentadas e discutidas.

Plagioclásio Os estudos petrográficos permitiram separar o plagioclásio em três populações distintas sendo os resultados químicos apresentados nas tabelas 2 c 3 . Esta lase foi separada $\mathrm{em}$ : i) fenocristais subédricos, tabulares e zonados; ii) fenocristais subédricos, tabulares e maclados, iii) e microcristais da matriz;

i) nos basaltos os fenocristais de plagioclásio subédricos, tabulares e zonados apresentam uma zonação do tipo oscilatória normal, com variações decrescentes e representativas para os intervalos de $\mathrm{An}_{02}$ ${ }_{85} \mathrm{c}$ de $\mathrm{An}_{84-72} \mathrm{em}$ direção às bordas dos grãos. A presença de zoneamento oscilatório normal bem desenvolvido nos fenocristais de plagioclásio, é uma feição comum nas rochas eruptivas orogênicas (Ewart 1 982). Nos andesitos basálticos, os conteúdos de anortita variam de $77 \%-74 \%$. Os dados químicos obtidos para o plagioclásio tabular, maclado e zonado dos basaltos da Península Fildes, estão $\mathrm{em}$ concordância com os dados apresentados por 
Bailey et al. (1989) para os basaltos do arco de ilhas de Kurile (noroeste do Pacífico). Os fenocristais de plagioclásio dos basaltos de Kurile apresentam uma variação semelhante no conteúdo de An cm relação aos basaltos da Península Fildes, geralmente $\mathrm{An}_{7(0-94}$, com a persistente ocorrência de núcleos cálcicos;

ii) os fenocristais subédricos, tabulares e maclados são, principalmente, do tipo bytownita-anortita $\left(\mathrm{An}_{63-87}\right)$, nos basaltos e $\mathrm{An}_{78-82}$ nos andesitos basálticos. Estes resultados estão de acordo com os estudos de Ewart (1982), que demostram a dominância da bytownita nos basaltos baixo-K e cálcio-alcalinos. Os teores da molécula de ortoclásio (Or) são baixos, atingindo em alguns casos $2 \%$. Os conteúdos de $\mathrm{FeO}(<1 \%)$ e o $\mathrm{MgO}(<0,21 \%)$ são baixos nos basaltos, sendo os valores mais elevados geralmente encontrados no feldspato da matriz. O FeO é um pouco mais elevado no plagioclásio dos andesitos basálticos. $\mathrm{O}$ teor de $\mathrm{Al}_{2} \mathrm{O}_{3}$ varia de $34,86 \%-27,72 \%$ nos basaltos e de $32,82 \%-26,89 \%$ nos andesitos basálticos. O alto conteúdo de anortita (An) detectado nos fenocristais de plagioclásio dos basaltos são característicos de basaltos de arcos de ilhas, sendo isto atribuído à $\mathrm{P}_{\mathrm{H} 2 \mathrm{O}}$, relativamente alta em magmas de arco (Arculus \& Wills 1980);

iii)os microcristais da matriz distinguem-se quimicamente dos fenocristais, pelo conteúdo mais baixo de anortita, ocorrendo plagioclásio do tipo labradorita $\left(\mathrm{An}_{53-63}\right)$ tanto nos basaltos como andesitos basálticos.

Piroxênio O piroxênio é o mineral málico dominante nas rochas vulcânicas básicas e intermediárias da Península Fildes e os dados de microfenocristais constam na Tabcla 4. A alteração desta fase na matriz impediu a obtenção de dados químicos para os micrólitos.

Tabela 2 - Composição química e fórmula estrutural de feldspatos das rochas básicas da Península Fildes. $M M=$ feldspato da matriz; STMZ = fenocristal subédrico, tabular, maclado e zonado; STM = fenocristal subédrico, tabular e maclado. $c$ = mícleo do grão; $b=$ borda de grấo.

\begin{tabular}{|c|c|c|c|c|c|c|c|c|c|c|c|c|c|}
\hline Basaltos & NFH & NF, itic) & 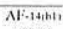 & Al-12ab? & $\mathrm{Nl} .14$ & $\mathrm{Al}-\mathrm{N}+(\mathrm{C})$ & Al:-3uthen & Af- $-\sin 2$ & Al: & $N=2.2$ & $A D=A$ & NI:-1:A & NI:121 \\
\hline & Mix & STSW\% & STMK/ & STM/. & SiM & STIN/ & sTsp & STMK. & INI & sis & SIM & MN & MIN \\
\hline $\mathrm{Si}()_{\mathrm{i}}$ & 54.06 & 47.29 & 48.88 & 50.87 & 4.81 & 45.20 & 46,91 & 47.25 & $5 ., 0 \mathrm{~K}$ & 47.23 & 45.77 & 53.91 & 53,30 \\
\hline $\mathrm{Al}_{2} \mathrm{O}_{4}$ & 27.72 & 33.21 & 31.49 & 30.65 & 3.71 & 34.86 & 33,65 & 32.80 & $27 . \times 4$ & 33,64 & 35.12 & $28 . \times 7$ & 29,20 \\
\hline 100 & 1.35 & 0.86 & 0.95 & 1.06 & 0.53 & 0.57 & 0.54 & $0.7 \mathrm{i}$ & 1.33 & 0.62 & 6.55 & 0.96 & 1.07 \\
\hline $\mathrm{MgO}$ & 0.24 & 0.05 & 0.11 & 0.11 & 0.07 & 0.01 & $0.0 \mathrm{x}$ & 0.05 & 0.10 & 0.07 & 0.05 & 0.4 & 0.14 \\
\hline (a) & 11.06 & 16.71 & $15,6.5$ & 14.13 & $1 \times .72$ & 18,66 & 17,47 & 17,908 & 11.52 & 17.71) & $1 \times .84$ & 12.26 & 12.53 \\
\hline $\mathrm{Na}_{\mathrm{A}_{2}} \mathrm{C}$ & 4.45 & 1.68 & 2.25 & 3,02 & 0.75 & 0.86 & $1.3 \mathrm{x}$ & 1.64 & 4.22 & 1.4 .4 & 0.72 & 4.08 & $4.0 \%$ \\
\hline $\mathrm{K}_{2} \mathrm{O}$ & 10.26 & 0.04 & 0.06 & 0.14 & 0.02 & 0.03 & 0.06 & 0.0 .22 & $0.2 \mathrm{~h}$ & $(0.3 x)$ & 0.02 & 0.80 & 0.11 \\
\hline Total & 99.12 & 99.85 & 99.39 & 99.96 & 99,61 & $1(x), 1 x$ & 160.15 & y9.54 & 49.34 & $i(x) .70$ & 101,07 & $1(x) .2 x$ & $(x), 4$ \\
\hline $\mathrm{si}^{* *}$ & 9.89 & 8.71 & 9.02 & 4,30 & $\mathrm{x} .32$ & $\mathrm{x} .3$ & $\mathrm{x} .63$ & 8.7.3 & $9, \mathrm{xx}$ & $\mathrm{x}, 04$ & $x, 37$ & 9.75 & 1, stis \\
\hline $\mathrm{Al}^{* *}$ & 5.97 & $7,2:$ & 6.84 & 6.54 & 7.5. & 7.58 & 7.29 & 7.16 & $5.9 y$ & 7.25 & 7.56 & 0.15 & 0..22 \\
\hline $10^{3 *}$ & 0.21 & 0.13 & 0.15 & 0.16 & $0.0 \mathrm{~s}$ & $0.0 \%$ & 0,09 & 0.11 & 0.20 & 0.10 & o. (uv & 0.15 & 0.16 \\
\hline $\mathrm{Mg}_{\mathrm{g}}{ }^{2+}$ & 0.06 & 0,02 & 0.03 & 0,03 & 0.02 & 0.00 & 0.02 & 0.02 & 0.03 & 0,02 & 0.011 & 0.04 & (1).04 \\
\hline $\mathrm{Ci}^{2}$ & 2.17 & 3,30 & 3.10 & 2.77 & , 37, & 3.69 & $3+4$ & 3,37 & 2.25 & 3,47 & 3.(n) & 2. $\mathrm{ik}$ & 2.41 \\
\hline $\mathrm{Nit}$ & 1.58 & 0.60 & 0.81 & 1.07 & 0.27 & 0.31 & 0.4 & (1).59 & 1.50 & o. 51 & 0.26 & 1.41 & 1.40 \\
\hline $\mathrm{K}^{*}$ & 0.006 & 0.01 & 0.02 & 0.03 & 0.01 & 0.01 & 0.02 & 0.01 & $0.6 \%$ & (10.100 & (x.) & 0.022 & 0.03 \\
\hline Tital & 20 & 20 & 20 & 20 & 20 & 20 & 20 & 20 & $2 n$ & 211 & 21) & 20 & 20 \\
\hline A & 41 & 15 & 21 & $2 \mathrm{~K}$ & 7 & $x$ & 18 & 15 & 39 & 13 & 7 & 37 & is \\
\hline An & 57 & xis & 79 & 72 & $y_{3}$ & 42 & 87 & xs & 54) & 87 & yi & 62 & ai \\
\hline$O_{1}$ & 2 & 0 & 0 & 1 & 0 & (1) & 0 & "1 & 2 & 6 & 0 & 1 & 1 \\
\hline
\end{tabular}

Tabela 3 - Composição química e fórmula estrutural de feldspatos das rochas intermediárias da Península Fildes. $M M=$ feldspato da matriz; STMZ = fenocristal subédrico, tabular; maclado e zonado; STM = fenocristal subédrico, tabular e maclado; $c=$ núcleo do grão; $b=$ borda de grão.

\begin{tabular}{|c|c|c|c|c|c|c|c|c|c|c|c|}
\hline Andesitos & $\mathrm{AF} \cdot 2 \mathrm{I}$ & $\mathrm{AF} \cdot 21$ & $A F-21$ (c) & $A F-21(1)$ & $A F=21$ & $\mathrm{AF} \cdot 21$ & $\mathrm{AF}=21$ & $A F=21$ & $A F \cdot 21$ & $A F_{-2 B}$ & $A F=2 B$ \\
\hline Tipo & STM & STM & SMTZ & SMTZ & MM & MM & MM & MM & MM & STM & STM \\
\hline $\mathrm{SiO}_{2}$ & $49,(10)$ & 48.57 & 49,34 & 50.19 & 53.64 & 53.61 & 55,74 & 53,90 & $54.2 \mathrm{~s}$ & 45.25 & 48.25 \\
\hline $\mathrm{Al}_{2} \mathrm{O}_{3}$ & 31,45 & 31.57 & 31.81 & 31,21 & 28.48 & 28.41 & 26,89 & 28,05 & 27.99 & 32.82 & 32.45 \\
\hline $\mathrm{FeO}$ & 1,02 & 0.97 & 0.87 & 0.91 & 1.14 & 1.35 & 1.39 & 1.52 & 1.18 & 0.70 & 0.75 \\
\hline $\mathrm{MgO}$ & $0 .\left(x_{3}\right.$ & $0.0 K_{3}$ & 0..$\left(x_{3}\right.$ & 0.08 & 0.16 & 0.16 & 0.35 & 0.18 & $0.0 \mathrm{~s}$ & $0,0 \mathrm{~s}$ & 0.07 \\
\hline $\mathrm{CaOO}$ & 15,53 & 15,73 & 15,31 & 14,62 & 11,96 & 11.75 & 10.13 & 11.57 & 11.93 & 16.44 & 16.22 \\
\hline $\mathrm{Na}_{2} \mathrm{O}$ & & 2.18 & 2.43 & 2.77 & 4,20 & 4.21 & 4.56 & 4.18 & 4.24 & 1,92 & 1.96 \\
\hline $\mathrm{K}_{2} \mathrm{O}$ & $0 .(x)$ & 0.11 & os & & 0.16 & $0,1,3$ & 0.17 & 0,24 & 0.24 & 0.03 & (0.03 \\
\hline Total & 99.48 & 99.17 & 99.89 & 99.91 & 99,75 & 99.62 & 99.53 & 99.64 & Y9.9.4 & $1(x), 24$ & Y9,72 \\
\hline $\mathrm{SI}^{*}$ & 9.04 & $8.9 x$ & 9.05 & 9.18 & 4.76 & 9.77 & 10,11 & 9.83 & 9.86 & 8.84 & 8.85 \\
\hline $\mathrm{Al}^{1+}$ & 6,83 & $6,8 \mathrm{~s}$ & 6,87 & 6.73 & 6.10 & (6.11) & 5.75 & 6.02 & $5,(x)$ & $7,0 \mathrm{~s}$ & 7.03 \\
\hline $\mathrm{Fe}^{2+}$ & 0.16 & 0.15 & 0.13 & 0,14 & (0.17 & 0.21 & 0.21 & 0.23 & 0.18 & 0.11 & 0.12 \\
\hline $\mathrm{Mg}^{2 *}$ & (0.)12 & 0.02 & 0.02 & 0,02 & 0,04 & 0.04 & 0.10 & 0.05 & 0.02 & 0.02 & 0.02 \\
\hline $\mathrm{Ca}^{2+}$ & 3.07 & 3.12 & 3.01 & 2.87 & 2.33 & 2.30 & 1.97 & 2,26 & 2.32 & 3.23 & 3.20) \\
\hline $\mathrm{Na}^{\circ}$ & $0,8,3$ & 0,78 & 0.86 & 0,98 & 1.48 & 1.49 & 1.71 & 1.48 & 1.49 & 0.63 & 0.70 \\
\hline$K^{*}$ & 0,02 & 0,03 & 0.02 & 0.03 & 0.04 & 0.0 .3 & 0.04 & $0 .\left(K_{3}\right.$ & $0.0 K_{6}$ & 0.01 & 0.01 \\
\hline Total & 20 & 20) & 20) & 20) & 20) & 20) & 20 & 20) & 20) & 20) & 20) \\
\hline $\mathrm{Ab}$ & 21 & 20) & 22 & 25 & 39) & 39 & 46 & 39) & 39 & 17 & 18 \\
\hline An & 78 & 79 & 77 & 74 & 61 & (6) & 53 & 6) & 60) & 82 & 82 \\
\hline Or & 1 & 1 & 1 & 1 & 1 & 1 & 1 & 2 & 1 & 0 & () \\
\hline
\end{tabular}

A composição química dos microfenocristais de clinopiroxênio (Fig. 6) enquadra-se no campo QUAD, que agrupa os piroxênios CaMg-Fe (Morimoto 1 988). Esta classificação indica o elevado conteúdo de $\mathrm{Ca}+\mathrm{Mg}+\mathrm{Fe}+2(\mathrm{Q})$ e a baixa quantidade de $2 \mathrm{Na}(\mathrm{J})$.

Os microfenocristais de clinopiroxênio das rochas básicas possuem uma composição de $\mathrm{WO}_{24-37} ; \mathrm{En}_{44-50} ; \mathrm{Fs}_{19-26}$. Nos andesitos basálticos os microfenocristais possuem uma composição em torno de $\mathrm{Wo}_{3}$; $\mathrm{En}_{45} ; \mathrm{Fs}_{17}$, semelhante à dos basaltos . De acordo com Ewart $(1982)^{38}$ a augita é o piroxênio cálcico dominante em basaltos de baixo-K e cálcio-alcalinos, diferentemente das associações de alto potássio onde geralmente ocorrem salita-diopsídio.

A pigeonita possui composição entre $\mathrm{WO}_{10-15} ; \mathrm{En}_{52-67} ; \mathrm{Fs}_{23-33}$ e restringe-se à matriz dos basaltos. $\mathrm{O}$ teor médio de $\mathrm{Al}_{2} \mathrm{O}_{3}$ na augita é de $2 \% \mathrm{c}$ na pigeonita em torno da unidade, indicando condições de cristalização sob baixa pressão.

No andesito basáltico AF-2l (Tabela 4) identifica-se bronzita $\left(\mathrm{WO}_{3}\right.$ ; $\mathrm{En}_{70} ; \mathrm{Fs}_{2(-27)}$. Neste ortopiroxênio, a concentração máxima de $\mathrm{CaO}$ determinada toi de 1,83\% aliado a um conteúdo de $\mathrm{MgO}$ de 25,69\% e de $\mathrm{Al}_{2} \mathrm{O}_{3}$ de $1,34 \%$.

Olivina A olivina está parcial ou totalmente alterada para carbonato, boulingita e iddingsita, ocorrendo fenocristais de olivina com porções inalteradas em apenas uma amostra de diabásio (AF-12B) inter-

Tabela + - Composição química e fórmula estrutural (6 oxigênios) de piroxênio dos basalnos e andesilos basálticos da Península Fildes.

\begin{tabular}{|c|c|c|c|c|c|c|c|c|c|c|c|}
\hline Litwlogi., & BAS & BAS & BAS & BAS & BAS & BAS & BAS & $\begin{array}{l}\text { ANI } \\
\text { BAS }\end{array}$ & $\begin{array}{l}\text { AND } \\
\text { BNS }\end{array}$ & $\begin{array}{l}\text { AND } \\
\text { BS }\end{array}$ & $\begin{array}{l}\text { AND } \\
\text { BNS }\end{array}$ \\
\hline Amastat & $A-1: A$ & $x=2 A$ & AF 14 & Al. 14 & AF: & Ar: & 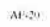 & & 列 & $\begin{array}{l}\text { BAS } \\
A=211\end{array}$ & \\
\hline $\sin =$ & 53.12 & 52,6 & 51.47 & 50,85 & $34 \%$ & $51.6 \times$ & 52.25 & $53,6.6$ & 54,46 & 52.42 & 51.08 \\
\hline $\mathrm{TiO}_{2}$ & 0.47 & (0.1) & 0.56 & 0.24 & 0.18 & 0.58 & 0,32 & 0.25 & 0.24 & 0.39 & 0.39 \\
\hline$A(1)$, & 1.35 & 2.4 & 2.17 & 2.57 & 1.36 & 1.86 & 0,98 & 2,30 & 1.34 & 2.25 & 2.61 \\
\hline (i) & 15.77 & 14.27 & 10.92 & $11.9 \mathrm{x}$ & 14.18 & 10.80 & 16,12 & 16,16 & $16 .+85$ & 9.87 & 8.67 \\
\hline $\mathrm{He}_{i} \mathrm{C}_{\mathrm{s}}$ & n.t. & $0.2 \%$ & 0,67 & 1.11 & nu. & 0.80 & (3.6) & nu.t. & n.t. & n.d. & 1.59 \\
\hline$\left(c_{1}\left(l_{1}\right)\right.$ & 0,00 & 0.01 & 0.05 & 0,000 & w.t.t. & $0,0,0$ & n.t. & nat. & 0.03 & 0,03 & $\theta m$ \\
\hline $\operatorname{Man} 3$ & 0.63 & 0.52 & 0.4 & $0.31)$ & 0.53 & 0.40 & 0.55 & $0.4 \mathrm{x}$ & 0.50 & 0.32 & 10.4 \\
\hline $\mathrm{N} 2 \mathrm{O}$ & 17.74 & 16.22 & 15.20 & $15.56 \%$ & 24.55 & 15.45 & 17.99 & $24.9 \%$ & 25.69 & 15.71 & 15.76 \\
\hline (at) & 11.77 & H.2.5 & 17.44 & 16,15 & 5.11 & 17.47 & 7.000 & 1.74 & 1.83 & 18,16 & $1 \times .57$ \\
\hline Notio & 0.16 & 0.26 & 0.28 & 0.25 & $0,0 \mathrm{ax}$ & 0.26 & 1.91 & 0.0 .5 & 0.01 & 0.29 & 0.33 \\
\hline $\left.\mathrm{K}_{1}{ }^{\prime \prime}\right)$ & m.at. & 0.017 & 0.12 & n.a.t. & 0.01 & n.s.t. & 0.02 & n.s. & n.t. & 0.01 & 0.07 \\
\hline Total & 101.31 & I101.45 & (9.12 & \%. & 100.95 & D9, 4 & 100.24 & (9)9? & 100,57 & $\%+4$ & $(1001266$ \\
\hline $\mathrm{TSi}$ & 1.97 & 1.94 & 1.937 & 1.915 & 1.977 & 1.94 & 1.955 & 1.052 & 1.967 & 1.953 & 1.922 \\
\hline TAI & 0.0 .3 & $0.0 \%$ & $0.06,3$ & 0,0185 & 0.023 & 0,06 & 0.043 & 0.048 & 0.033 & 0.047 & $0.477 \mathrm{x}$ \\
\hline $\mathrm{TH}$ & n... & n.t. & n.t. & n.t. & n.u. & n.u. & 0,002 & n.a.t. & n...t. & n...1. & i. i. \\
\hline MHAN & $0,09,9$ & 0016 & 0.013 & 0.029 & 0.034 & 0,022 & nid. & 0.051 & 0.024 & 0,052 & 0.036 \\
\hline MITi & 0.011 & 0.014 & 0.016 & 0,021 & 0,005 & 0,017 & $0.00 \%$ & 0.0077 & O.OKN, & 0.011 & 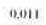 \\
\hline Nille" & n.a.t. & wateis & 0.019 & 0.031 & n.a.t. & 0.023 & 0.102 & nut. & n.t. & wis. & 0.031 \\
\hline MHe & n.i. & 0.041 & 0.079 & 0.072 & n.t. & 0.073 & n.t. & n.d. & n.t. & 0.06 .4 & 0.04 \\
\hline Maci & n.d. & nut. & 0.012 & w.t. & nu. & 0.009 & n.t. & w.t. & 0.091 & 1..601 & n.a.t. \\
\hline MIM!: & $0.95 x$ & $0.8 \%$ & $0 . \times 52$ & 0.846 & 0.961 & 0.866 & (0.xx) & 0.912 & "I.Y. & 0.872 & $(0 . X(1)$ \\
\hline MIME: & 0.018 & nat. & n.t. & n.t. & 0.35 & n.t. & 0.14 & 0.411 & 0.415 & n.t. & nis. \\
\hline $\mathrm{M} 2 \mathrm{~F}^{*}$ & $0.1 \times 6$ & $(1,3 \%)$ & 40.26 .5 & 0.305 & 0.426 & 0.266 & 0.514 & 0.501 & $0.12 \%$ & 0.23 & 0.229 \\
\hline M2Mn & o.n: & 0.016 & 10011 & 0.012 & 0.016 & 0.013 & 0.017 & nows & 0.015 & 9.01 & 0.011 \\
\hline $\mathrm{NEC} ;$ & 08.4 .5 & 0.563 & 0.703 & 10.66.4 & 0.197 & 0.703 & $0.2 \times 1$ & a.s.kex & 0.971 & 10.725 & 0.736 \\
\hline NEN. & 10011 & (9011) & 0.921 & $0.01 \mathrm{~K}$ & 0.005 & $0.01 \%$ & $0 ., 477$ & 0.6013 & 01001 & (10.21 & 0.024 \\
\hline MLK & w.4. & 0.0603 & 0.001 & in.ul. & 0,001 & nut & 00,501 & n.d. & nul & n.t. & $\theta(K) I$ \\
\hline Cotums & 4 & 3997 & (x) & 4 & 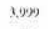 & 4 & 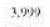 & 4 & 4 & 4 & $(x)$ \\
\hline$w_{i}$ & 24 & $\Rightarrow$ & 37 & 4 & 10 & 36 & 15 & 1 & 4 & 78 & 78 \\
\hline in & 50 & 47 & 4 & 4 & 67 & 45 & 52 & 70 & 70 & 45 & 45 \\
\hline If & 26 & 24 & 1) & 22 & 23 & 19 & $3 x$ & 27 & 26 & 17 & 17 \\
\hline
\end{tabular}

pretada como cogenético ao vulcanitos estudados (Tabela 5).

A olivina é do tipo crisolita com teor de Fo de 79 a $81 \%$. Ewart (1982) conclui que basaltos de baixo-K e cálcio-alcalinos contêm, preferencialmente, olivina rica em magnésio, com intervalo de Fo entre 70-85\%. Bailey et al. (1989) encontraram fenocristais de olivina em todas as amostras de basaltos de Kurile, com conteúdo de Fo no intervalo de 65 até $93 \%$, sendo que a olivina é menos comum nos andesitos basálticos. O conteúdo de $\mathrm{CaO}$ encontra-se no intervalo de 0,23 a $0,27 \%$. Os teores de $\mathrm{NiO}$ e $\mathrm{Cr}_{2} \mathrm{O}_{3}$ são baixos e o $\mathrm{MnO}$ apresenta concentrações da ordem de 0,25 a $0,33 \%$.

Óxidos Os minerais denominados óxidos limitam-se as fases pertencentes ao sistema $\mathrm{FeO}-\mathrm{Fe}_{2} \mathrm{O}_{3}-\mathrm{TiO}_{2}$, e os resultados estão representadas na Tabela 6 .

O teor de TiO, da magnetita nos basaltos e andesito basáltico (AF21) varia de 5,64 a $8,88 \%$. Os conteúdos de $\mathrm{Cr}_{2} \mathrm{O}_{3}$ e $\mathrm{MnO}$ para as lases óxidos são bastante baixos $(<<1 \%)$. O conteúdo de $\mathrm{MgO} \mathrm{em}$ geral é de 2,5\%, comum em magnetita cristalizada em alta temperatura. A concentração de ulvoespinélio (ULV) na magnetita varia de $16 \%$ a $25 \%$. 


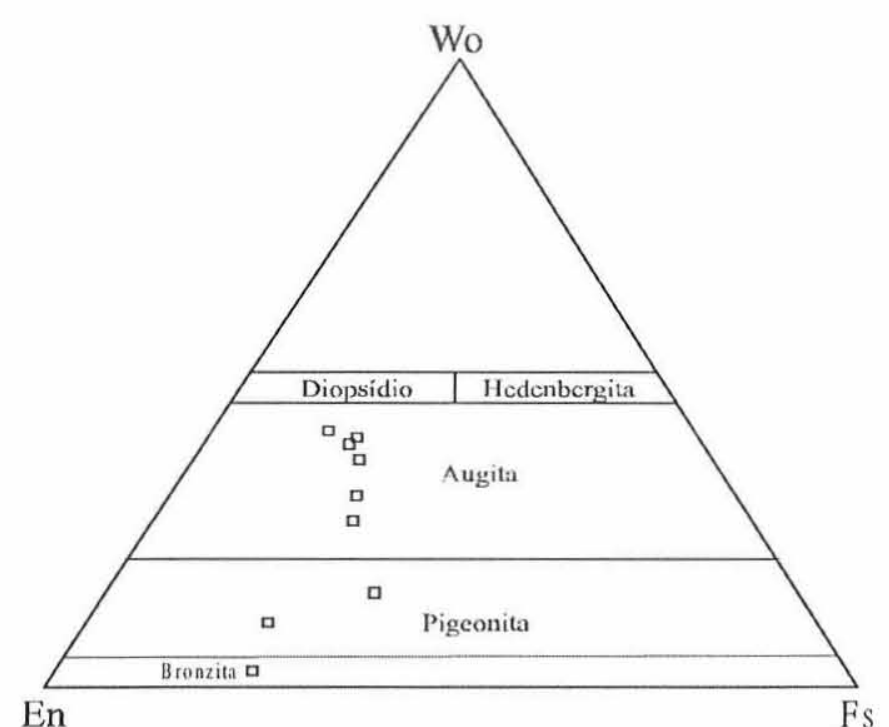

Figura 6 - Classificą̧ão química do piroxênio (Morimoto 1988) das rochas básicas e intermediárias da Península Fildes.

Tabela 5 - Composição química e fórmula estrutural (4 oxigênios) de olivina de un diabásio da Península Fildes.

\begin{tabular}{crrrrr}
\hline Amostra & AF-12B & AF-12B & AF-12B & AF-12B & AF-12B \\
\hline $\mathrm{SiO}_{2}$ & 39,50 & 39,82 & 39,41 & 39,77 & 39,38 \\
$\mathrm{TiO}_{2}$ & n.d. & n.d. & n.d. & 0,02 & n.d. \\
$\mathrm{Al}_{2} \mathrm{O}_{3}$ & 0,05 & 0,04 & 0,05 & 0,07 & 0,08 \\
$\mathrm{FeO}$ & 17,93 & 18,30 & 17,52 & 17,79 & 19,05 \\
$\mathrm{MnO}$ & 0,29 & 0,30 & 0,25 & 0,26 & 0,32 \\
$\mathrm{MgO}$ & 41,94 & 41,85 & 41,59 & 41,77 & 41,33 \\
$\mathrm{CaO}$ & 0,24 & 0,26 & 0,26 & 0,27 & 0,23 \\
$\mathrm{NiO}$ & 0,07 & 0,01 & n.d. & 0,03 & 0,02 \\
$\mathrm{Cr} \mathrm{O}_{3}$ & 0,02 & n.d. & 0,01 & n.d. & 0,01 \\
$\mathrm{Total}$ & 100,04 & 100,58 & 99,09 & 99,98 & 100,42 \\
$\mathrm{Si}$ & 1,00 & 1,01 & 1,01 & 1,01 & 1,00 \\
$\mathrm{Ti}$ & n.d. & n.d. & n.d. & n.d. & n.d. \\
$\mathrm{Al}$ & 0,01 & 0,01 & 0,01 & 0,01 & 0,01 \\
$\mathrm{Fe}{ }^{2+}$ & 0,38 & 0,39 & 0,38 & 0,38 & 0,41 \\
$\mathrm{Mn}$ & 0,01 & 0,01 & 0,01 & 0,01 & 0,01 \\
$\mathrm{Mg}$ & 1,59 & 1,59 & 1,59 & 1,58 & 1,57 \\
$\mathrm{Ca}$ & 0,01 & 0,01 & 0,01 & 0,01 & 0,01 \\
$\mathrm{Cations}$ & 3,00 & 3,02 & 3,01 & 3,00 & 3,01 \\
$\mathrm{Fa}$ & 19,00 & 20,00 & 19,00 & 19,00 & 21,00 \\
$\mathrm{Fo}$ & 81,00 & 80,00 & 81,00 & 81,00 & 79,00 \\
\hline
\end{tabular}

n.d. = não detectado

GEOTERMOMETRIA Para determinar a temperatura de cristalização do par clinopiroxênio-ortopiroxênio ( \pm magnetita) do andesito basáltico AF-21 da Península Fildes utilizou-se o programa de Frost \& Lindsley (1992), denominado Ca-QUILF (Piroxênio cálcico-QuartzoUlvoespinélio-Ilmenita-Fayalita). Conforme recomendação dos autores foram considerados os seguintes aspectos na escolha das análises: a) os pares de piroxênio considerados em equilíbrio não apresentaram feições petrográficas de reação, reabsorção nem zoneamento; b) o equilíbrio aparentemente foi mantido após a cristalização, não sendo evidenciadas feições de exsolução; c) as análises obtidas estão dentro dos limites de incerteza da composição do piroxênio, especialmente do conteúdo de $\mathrm{Fe}^{+3}$. Foram testados dois pares de piroxênio e acrescen-
Tabela 6 - Composição quimica e fórmula estrutural (23 oxigênios) de minerais opacos das rochas básicas e intermediária da Península Fildes.

\begin{tabular}{|c|c|c|c|c|c|}
\hline Amostra & AF-19 & $\mathrm{AF} 14$ & AF-14 & AF-21 & AF-21 \\
\hline $\mathrm{SiO}_{2}$ & 0,11 & 0,12 & 0,14 & 0,13 & 0,09 \\
\hline $\mathrm{TiO}_{2}$ & 6,74 & 8,88 & 7,33 & 6,83 & 5,64 \\
\hline $\mathrm{Al}_{2} \mathrm{O}_{3}$ & 5,99 & 4,39 & 5,53 & 4,68 & 2,82 \\
\hline $\mathrm{FcO}$ & 32,22 & 35,52 & 34,47 & 32,29 & 34,46 \\
\hline $\mathrm{Fe}_{2} \mathrm{O}_{3}$ & 50,26 & 47,14 & 47,90 & 50,46 & 53.83 \\
\hline $\mathrm{MnO}$ & 0,27 & 0,30 & 0,32 & 0,32 & 0,27 \\
\hline $\mathrm{MgO}$ & 3,67 & 2,53 & 2,21 & 3,23 & 0,94 \\
\hline $\mathrm{NiO}$ & 0,01 & 0,01 & n.d. & 0,01 & n.d. \\
\hline $\mathrm{Cr}_{2} \mathrm{O}_{3}$ & 0,15 & 0,15 & 0,19 & 0,18 & 0,12 \\
\hline Total & 99,42 & 99,04 & 98,09 & 98,13 & 98,17 \\
\hline $\mathrm{Si}$ & 0,03 & 0,04 & 0,04 & 0,04 & 0,03 \\
\hline $\mathrm{Ti}$ & 1,47 & 1,97 & 1,64 & 1,52 & 1,29 \\
\hline $\mathrm{Al}$ & 2,04 & 1,52 & 1,93 & 1,63 & 1,01 \\
\hline $\mathrm{Fe}^{2+}$ & 7,80 & 8,76 & 8,56 & 8 & 8,78 \\
\hline $\mathrm{Fe}^{3+}$ & 10,95 & 10,46 & 10,70 & 11,24 & 12,34 \\
\hline $\mathrm{Mn}$ & 0,07 & 0,07 & 0,08 & 0,08 & 0,07 \\
\hline $\mathrm{Mg}$ & 1,58 & 1,11 & 0,98 & 1,43 & 0,43 \\
\hline $\mathrm{Ni}$ & 0,01 & 0,01 & n.d. & 0,01 & n.d. \\
\hline $\mathrm{Cr}$ & 0,03 & 0,04 & 0,05 & 0,04 & 0,03 \\
\hline Total & 23,98 & 23,98 & 23,98 & 23,98 & 23,98 \\
\hline UVL & 18,00 & 25,00 & 21,00 & 19,00 & 16,00 \\
\hline
\end{tabular}

tada, posteriormente, duas análises de magnetita. Dada a pequena variação composicional destas fases os resultados obtidos foram muito semelhantes.

O piroxênio e magnetita escolhidos constituem microfenocristais, razão pela qual fixou-se a pressão de 1 até 1500 bar com intervalos de 500 bar, conforme sugestão de Frost \& Lindley (1992). Inicialmente utilizou-se dois pares de clinopiroxênio-ortopiroxênio com as composições fixadas, obtendo-se as temperaturas $1065^{\circ} \mathrm{C} \pm 26^{\circ} \mathrm{C}$ ( 1 bar), $1067^{\circ} \mathrm{C} \pm 25^{\circ} \mathrm{C}$ (500 bar), $1069^{\circ} \mathrm{C} \pm 25^{\circ} \mathrm{C}$ (1000 bar) e $1071^{\circ} \mathrm{C} \pm 24^{\circ} \mathrm{C}$ (1500 bar). O baixo grau de incerteza sugere que o ortopiroxênio e a augita permaneceram próximo ao equilíbrio no andesito basáltico. Num segundo teste realizado permitiu-se a variação composicional da augita, dentro dos mesmos intervalos de pressão. As temperaturas de equilíbrio obtidas foram de $1062^{\circ} \mathrm{C}(1 \mathrm{bar}), 1067^{\circ} \mathrm{C}(1000 \mathrm{bar}) \mathrm{e}$ $1069^{\circ} \mathrm{C}$ (1500 bar). A variação composicional calculada para a augita ficou muito próxima da analisada e o grau de incerteza igual a zero. Posteriormente adicionou-se à rotina do programa, a composição da magnetita do andesito basáltico, mantendo-se as mesmas variaçōes de pressão. Inicialmente fixou-se a composição das três fases (ortopiroxênio + augita + espinélio) obtendo-se valores de temperaturas de $1072^{\prime \prime} \mathrm{C} \pm 15^{\prime \prime} \mathrm{C}$ ( 1 bar), $1074^{\circ} \mathrm{C} \pm 15^{\prime \prime} \mathrm{C}\left(500\right.$ bar), $1076^{\prime \prime} \mathrm{C} \pm$ $14^{\prime \prime} \mathrm{C}(1000$ bar $)$ e $1078^{\circ} \mathrm{C} \pm 14^{\circ} \mathrm{C}(1500$ bar $)$. Admitindo-se uma variação composicional para augita e para o número de magnésio do espinélio ( 3 cátions/ 4 oxigênios) o teste indicou uma temperatura de $1062^{\circ} \mathrm{C}$ (1 bar), $1065^{\circ} \mathrm{C}$ (500 bar), $1067^{\circ} \mathrm{C}$ (1000 bar) e $1069^{\circ} \mathrm{C}(1500$ bar) para um grau de incerteza igual a zero. Constatou-se uma pequena variação entre os conteúdos da molécula de En e Wo analisados e calculados. O resultado sugere condições de equilíbrio do espinélio com os dois piroxênios no andesito basáltico AF-2I dentro do intervalo de temperatura de $1065^{\circ} \mathrm{C}-1070^{\circ} \mathrm{C}$ para pressões da ordem de 1 bar a 1500 bar (Tab. 7). As temperaturas calculadas estão próximas as obtidas para andesitos por outros autores (Wilcox 1954 - Paracutin - 55\% $\mathrm{SiO}-1070^{\circ} \mathrm{C}-1110^{\circ} \mathrm{C}$ - medidas de campo; Marsh \& Carmichael 1974 - Lassen, USA - 55\% $\mathrm{SiO}_{2}-1000^{\circ} \mathrm{C}$ - geotermometria com óxidos de Fe-Ti; Ewart 1976 - Tonga - 53\%-55\% $\mathrm{SiO}_{2}-1050^{\circ} \mathrm{C}-$ $1080^{\circ} \mathrm{C}$ - geotermometria com clinopiroxênio-ortopiroxênio; Luhr \& 


\begin{tabular}{|c|c|c|c|c|}
\hline A & B & C & $\begin{array}{l}\text { Clinopiroxênio } \\
\text { analisado }\end{array}$ & $\begin{array}{l}\text { Clinopiroxênio } \\
\text { calculado }\end{array}$ \\
\hline 1 & 1035 & 0 & $\begin{array}{l}\text { XEn } 0,45558 \\
\text { XWo } 0,37854 \\
\text { XFs } \\
\text { XFe }\end{array}$ & $\begin{array}{ll}\text { XEn } & 0,46814 \\
\text { XWo } & 0,37606 \\
\text { XFs } & 0,15580 \\
\text { XFe } & 0,24970\end{array}$ \\
\hline 500 & 1038 & 0 & $\begin{array}{l}\text { XEn } 0,45558 \\
\text { XWo } 0,37854 \\
\text { XFs } \\
\text { XFe }\end{array}$ & $\begin{array}{l}\text { XEn } 0,46819 \\
\text { XWo } 0,37556 \\
\text { XFs } 0,15625 \\
\text { XFe } 0,25022\end{array}$ \\
\hline 1000 & 1340 & 0 & $\begin{array}{l}\text { XEn } 0.45558 \\
\text { XWo } 0,37854 \\
\text { XFs } \\
\text { XFe }\end{array}$ & $\begin{array}{ll}\text { XEn } & 0,46824 \\
\text { XWo } & 0,37506 \\
\text { XFs } & 0,15670 \\
\text { XFe } & 0,25074\end{array}$ \\
\hline 1500 & 1342 & 0 & $\begin{array}{l}\text { XEn } 0.45558 \\
\text { XIVo } 0,37854 \\
\text { XFs } \\
\text { XFe }\end{array}$ & $\begin{array}{ll}\text { XEn } & 0.46828 \\
\text { XWo } & 0.37457 \\
\text { XFs } & 0.15714 \\
\text { XFe } & 0.25126\end{array}$ \\
\hline
\end{tabular}

\begin{tabular}{|c|c|c|c|}
\hline \multicolumn{4}{|c|}{ Composição fixa da augita } \\
\hline A & B & $\mathrm{C}$ & $\begin{array}{l}\text { Clinopiroxênio } \\
\text { analisado }\end{array}$ \\
\hline 1 & 1038 & 26 & $\begin{array}{l}\text { XEn } 0,45558 \\
\text { XWo } 0,37854 \\
\text { XFs } \\
\text { XFe }\end{array}$ \\
\hline 500 & 1340 & 25 & $\begin{array}{l}\text { XEn } 0,45558 \\
\text { XWo } 0,37854 \\
\text { XFs } \\
\text { XFe }\end{array}$ \\
\hline 1000 & 1342 & 25 & $\begin{array}{l}\text { XEn } 0,45558 \\
\text { XIVo } 0,37854 \\
\text { XFs } \\
\text { XFe }\end{array}$ \\
\hline 1500 & 1344 & 24 & $\begin{array}{l}\text { XEn } 0,45558 \\
\text { XWo } 0,37854 \\
\text { XFs } \\
\text { XFe }\end{array}$ \\
\hline
\end{tabular}

\section{A - Pressão (bar) \\ B - Temperatura $\left({ }^{\circ} \mathrm{C}\right)$ \\ C - Grau de incerteza $\left({ }^{\circ} \mathrm{C}\right)$}

$\mathrm{XEn} \mathrm{En} /(\mathrm{En}+\mathrm{W} \mathrm{V}+\mathrm{Fs})$

$\mathrm{XWo} \mathrm{Wo} /(\mathrm{En}+\mathrm{Wo}+\mathrm{Fs})$

$\mathrm{XFs} \mathrm{Fs} /(\mathrm{En}+\mathrm{Wo}+\mathrm{Fs})$

Composição fixa do ortopiroxênio $\mathrm{XEn}=0,69898$

$\mathrm{XWo}=0,03496$

\section{Magnetita}

$\mathrm{NT} i=\mathrm{n}^{\circ}$ de átomos de Ti $(3$ cátions $/ 4 \mathrm{O})$

$\mathrm{NMg}=\mathrm{n}^{\circ}$ de átomos de $\mathrm{Mg}(3$ cátions/4 O)

$\mathrm{NMn}=\mathrm{n}^{\circ}$ de átomos de Mn (3 cátions/4 O)

\begin{tabular}{|c|c|c|c|c|}
\hline A & B & $\mathrm{C}$ & $\begin{array}{l}\text { Clinopiroxênio } \\
\text { analisado }\end{array}$ & $\begin{array}{l}\text { Espinćlio } \\
\text { analisado }\end{array}$ \\
\hline 1 & 1345 & 15 & $\begin{array}{l}\text { XEn } 0,45558 \\
\text { XWo } 0,37854 \\
\text { XFs } \\
\text { XFe }\end{array}$ & $\begin{array}{l}\text { NTi } 0,19130 \\
\text { NMg } 0,1638 \\
\text { NMn } 0.0055\end{array}$ \\
\hline 500 & 1347 & 15 & $\begin{array}{l}\text { XEn } 0,45558 \\
\text { XWo } 0,37854 \\
\text { XFs } \\
\text { XFe }\end{array}$ & $\begin{array}{l}\text { NTi } 0,19130 \\
\text { NMg } 0,1638 \\
\text { NMn } 0,0055\end{array}$ \\
\hline 1000 & 1349 & 14 & $\begin{array}{l}\text { XEn } 0.45558 \\
\text { XWo } 0.37854 \\
\text { XFs } \\
\text { XFe }\end{array}$ & $\begin{array}{l}\text { NTi } 0,19130 \\
\text { NMg } 0,1638 \\
\text { NMn } 0,0055\end{array}$ \\
\hline 1500 & 1351 & 14 & $\begin{array}{l}\text { XEn } 0,45558 \\
\text { XWo } 0,37854 \\
\text { XFs } \\
\text { XFe }\end{array}$ & $\begin{array}{l}\text { NTi } 0.19130 \\
\text { NMg } 0.1638 \\
\text { NMn } 0.0055\end{array}$ \\
\hline
\end{tabular}

Variando $\mathrm{NMg}$ do espinélio e a composição da augita

\begin{tabular}{|c|c|c|c|c|c|c|}
\hline$\Lambda$ & B & $\mathrm{C}$ & $\begin{array}{l}\text { Clinopiroxênio } \\
\text { analisado }\end{array}$ & $\begin{array}{l}\text { Clinopiroxênio } \\
\text { calculado }\end{array}$ & $\begin{array}{l}\text { Espinćlio } \\
\text { analisado }\end{array}$ & $\begin{array}{l}\text { Espinćlio } \\
\text { calculado }\end{array}$ \\
\hline 1 & 1335 & 0 & $\begin{array}{l}\text { XEn } 0.45558 \\
\text { XWo } 0.37854 \\
\text { XFs } \\
\text { XFc }\end{array}$ & $\begin{array}{lr}\text { XEn } & 0,46814 \\
\text { XWo } & 0,37606 \\
\text { XFs } & 0,15580 \\
\text { XFe } & 0,24970\end{array}$ & $\begin{array}{l}\text { NTi } 0,19130 \\
\text { NMg } 0,1638 \\
\text { NMn } 0,0055\end{array}$ & $\begin{array}{l}\text { NTi } 0,19130 \\
\text { NMg } 0,16802 \\
\text { NMn } 0,0055\end{array}$ \\
\hline 500 & 1338 & 0 & $\begin{array}{l}\text { XEn } 0,45558 \\
\text { XWo } 0,37854 \\
\text { XFs } \\
\text { XFe }\end{array}$ & $\begin{array}{ll}\text { XEn } & 0,46819 \\
\text { XIVo } & 0,375.56 \\
\text { XFs } & 0,15625 \\
\text { XFe } & 0,25022\end{array}$ & $\begin{array}{l}\text { NTi } 0,19130 \\
\text { NMg } 0,1638 \\
\text { NMn } 0,0055\end{array}$ & $\begin{array}{l}\text { NTi } 0,19130 \\
\text { NMg } 0,16785 \\
\text { NMn } 0,0055\end{array}$ \\
\hline 1000 & 1340 & 0 & $\begin{array}{l}\text { XEn } 0,45558 \\
\text { XWo } 0,37854 \\
\text { XFs } \\
\text { XFe }\end{array}$ & $\begin{array}{ll}\text { XEn } & 0,46824 \\
\text { XWo } & 0,37506 \\
\text { XFs } & 0,15670 \\
\text { XFe } & 0,25074\end{array}$ & $\begin{array}{l}\text { NTi } 0,19130 \\
\text { NMg } 0,1638 \\
\text { NMn } 0,0055\end{array}$ & $\begin{array}{l}\text { NTi } 0,19130 \\
\text { NMg } 0,16768 \\
\text { NMn } 0,0055\end{array}$ \\
\hline 1500 & 1342 & 0 & $\begin{array}{l}\text { XEn } 0.45558 \\
\text { XWo } 0.37854 \\
\text { XFs } \\
\text { XFe }\end{array}$ & $\begin{array}{ll}\text { XEn } & 0,46828 \\
\text { XWo } & 0,37457 \\
\text { XFs } & 0,15714 \\
\text { XFe } & 0,25126\end{array}$ & $\begin{array}{l}\text { NTi } 0,19130 \\
\text { NMg } 0,1638 \\
\text { NMn } 0,0055\end{array}$ & $\begin{array}{l}\text { NTi } 0,19130 \\
\text { NMg } 0,16752 \\
\text { NMn } 0,0055\end{array}$ \\
\hline
\end{tabular}

Carmichael 1980 - Colima - $56 \% \mathrm{SiO}_{2}-1030^{\circ} \mathrm{C}-1140^{\circ} \mathrm{C}$ - isótopos de oxigênio).

CONCLUSŌES Nos diagramas convencionais utilizados para separar rochas toleiíticas e cálcio-alcalinas as rochas vulcânicas da Península Fildes bordejam a linha que delimita estas sérics. No entanto, a concentração elevada de $\mathrm{Al}_{2} \mathrm{O}_{3}, \mathrm{Rb}, \mathrm{Ba}, \mathrm{Sr}$ e o leve enriquecimento em ETRL em relação aos elementos terras raras pesados (ETRP) atesta a natureza cálcio-alcalina dos vulcanitos da península. Esta afinidade é melhor ilustrada no diagrama IA (índice de alcalinidade) versus $\mathrm{Al}_{2} \mathrm{O}_{3}$

Os conteúdos de $\mathrm{Ni}, \mathrm{Cr}$, Co e $\mathrm{MgO}$ das rochas básicas da Península Fildes são inferiores àqueles encontrados em composições básicas primárias e atestam a condição evoluída destas magmas.

As razōes iniciais de ${ }^{87} \mathrm{Sr} /{ }^{86} \mathrm{Sr}$ de 0,7033 a $0,7037,{ }^{143} \mathrm{Nd} / /^{144} \mathrm{Nd}$ de 0,512959 e 0,512967 e os valores de $\varepsilon N d$ (para $\mathrm{t}=55 \mathrm{Ma}$ ) de $+6,52$ $\mathrm{e}+6,72$ sugerem que as rochas foram geradas a partir da fusão parcial do manto litosférico sem a interferência de outros fatores petrogenéticos.

A química mineral dos basaltos indica uma associação de fenocristais de plagioclásio rico em cálcio (bytownita-anortita) + augita \pm olivina + magnetita. A composição rica em cálcio dos fenocristais de plagioclásio, com zoneamento oscilatório normal, é típica das séries de baixo-K e cálcio-alcalina. Na matriz, o plagioclásio é composicionalmente do tipo labradorita. A augita é o clinopiroxênio mais abundante e a pigeonita é rara, restringindo-se a matriz dos basaltos. Fenocristais de bronzita são observados apenas nos andesitos basálticos. A olivina é do tipo crisolita com teor de Fo variando de 79 a $81 \%$, composição esta comum $\mathrm{em}$ associações básicas de baixo-K e cálcio-alcalina. A fase óxido determinada é magnetita com conteúdo de $\mathrm{TiO}_{2}$ dentro do intervalo 5,64 a 8,88 .

Dados de química mineral do par clinopiroxênio-ortopiroxênio ( \pm magnetita) do andesito basáltico (AF-21), utilizados no programa Ca-QUILF, sugerem uma temperatura de cristalização e um equilíbrio destas fases dentro do intervalo de $1065^{\circ} \mathrm{C}-1070^{\circ} \mathrm{C}$ para pressões da ordem de lbar a 1500 bar. Apesar do número reduzido de dados podese considerar que os valores encontrados são coerentes com as temperaturas determinadas para sistemas andesíticos basálticos.

A condição de equilíbrio do par clinopiroxênio-ortopiroxênio ( \pm magnetita), aliada à composição cálcica do plagioclásio, é coerente com a hipótese originalmente postulada de cristalização fracionada para a evolução dos vulcanitos da Península Fildes. A investigação dos dados de química mineral, litoquímica e isotópicos mostra que os mesmos são também coerentes com esta hipótese, não sendo encontradas evidências que sugerissem a interferência de outros fatores petrogenéticos, como mistura de magma e/ou assimilação, para explicar a origem e evolução destas rochas.

Agradecimentos Ao CNPq (proc.142181/97 e 520036/96-4), pelo apoio financeiro, ao PROANTAR e a SECIRM pelo apoio logístico, ao Centro de Estudos em Petrologia e Geoquímica-lGUFRGS e ao PRONEX pelas facilidades de infra-estrutura. Os autores agradecem aos revisores da RBG pelas críticas e sugestões. 


\section{Referências}

Arculus R.J. \& Wills K.J.A. 1980. The petrology of plutonic blocks and inclusions from Lesser Antilles Arc. J. Petrol., 21:743-799.

Bailey J.C., Frovola T.I., Burikova I.A. 1989. Mineralogy, geochemistry and petrogenesis of Kurile Island-Arc Basalts. Contrib. Mineral. Petmol., 102:265-280.

Baker P.E. 1982. Evolution and classification of orogenic volcanic rocks. In R.S. Thorpe (ed.) Andesites: orogenic andesites and related rocks. London, J. WViley, $11-23$

Barker P.F. 1970. Magnetic lineations in the Scotia Sea. In R.J. Adie (ed.) Antarctic Geolog and Geophysics. Oslo, Universitetsforlaget. 17-26.

Barker P.F. \& Griffiths D.H. 1972. The evolution of the Scotia Ridge and Scotia Sea. Philosophical Trasactions of the Royal Society of London, 271 ( Series A):151-183.

Ewart A. 1976. A petrological study of the younger Tonga andesites and dacites, and the olivine tholeites of Niua Fo' oou Island, S.W. Pacific. Contrib. Mineral. Petrol. 58:121.

Ewart A. 1982. The mineralogy and petrology of Tertiary-Recent orogenic volcanic rocks with special reference to the andesitic-basaltic compositional range. In R.S. Thorpe (ed.) Andesites: orogenic andesites and related rocks. London, J. Wiley, 25-87.

Figueiredo A.M.G. \& Marques L.S. 1989. Determination of rare earths and other trace elements in the Brazilian Geological Standards BB-I and GB-I neutron activation analysis. Geoch. Bras., 3(1):1-8.

Frost B.R. \& Lindsey D.H. 1992. Equilibria among Fe-ti oxides, pyroxenes.olivine and quartz: Part II. Application. Am. Mineral. 77:1004-1020

Hawkes D.D. 1961. The geology of the South Shetland Islands: I.The petrology of King George Island. Falkland Islands Dependencies Surver Scientific Reparts, 26:28 p.

Irvine T.N.\& Baragar W.R.A. 1971. A guide to the chemical classification of the common volcanic rocks. Can. J. Earth Sci., 8:523-48.

Jin Q., Kuang F., Ruan H., Xing G. 1991. Island arc volcanism and magmatic evolution in Fildes peninsula, King George Island, Antarctica. In: Abstracts Sixth International Synposium on Antartic Earth Sciences. National Institutte of Polar Research, Resumos Expandidos, 250-255.

Le Bas M.J., Le Maitre R.W.. Streckeisen A., Zanettin B. 1986. A chemical classification of volcanic rocks based on the total alkali-silica diagram. J. Petrol, 25:745-750.

Lindsey D.H. \& Frost B.R. 1992. Equilibria among Fe-Ti oxides, pyroxenes, olivine and quartz: Part 1. Teory. Am. Mineral., 77:987-1003.

Lulur J.F. \& Carmichael I.S.E. 1980. The Colima volcanic complex, Mexico. Contrib. Mineral. Petrol. 71:343-372.

Machado A. Chemale Jr. F Lima E.F. Figueiredo A. M. 1998 Petrologia das Rochas Vulcânicas da Península Fildes, Ilha Rei George, Antártica. Pesquisas, 25 (1):35-42.
Marsh B.D. 1982. The Aleutians. In R.S. Thorpe (ed.) Andesites: orogenic andesites and related rocks. London, J. Wiley, 99-114.

Marsh B.D. \& Carmichael I.S.E. 1974. Benioff zone magmatism. J. Geophrs. Res. 79:11961206.

Miyashiro A. 1974. Volcanic rocks in island arcs and active continental margins. Am. Jour. Sci., 274:321-355.

Morimoto N.C. 1988. Nomenclature of pyroxenes. Am. Mineral. 73(9-10):1123-1133.

Myers J.D., Marsh B.D. Sinha A.K 1986. Geochemical and strontium isotopic characteristics of parental Aleutian Arc Magmas: evidence from the basaltic lavas of Atka Contrib, Mineral Petrol, 94:1-11.

Nakamura N 1974. Determination of REE, Ba, Fe, Mg, Na and $\mathrm{K}$ in carbonaceous and ordinary chondrites. Geoch. Cosmoch. Acta, 38:757-775.

Pearce J.A. 1982. Trace element characteristics of lavas from destructive plate boundaries. In R.S. Thorpe (ed.) Andesites: orogenic andesites and related rocks. London, J. Wiley, 525-548.

Smellie J.L. Pankhurst R., Thomson M.R.A., Davies R. 1984. The geology of the South Shetland Islands: stratigraphy, geochemistry and evolution, British Antarctic Surver Scientific Reports, 87: 84 p.

Thompson R.N. et. al. 1983. Continental flood basalts...arachnids rule ok? In C.J. Haewkesworth \& M.J. Norry (eds.) Continental basalts and mantle xenoliths. Nantwicl. Shiva. 158-185.

Tyrrel G. WV. 1945. Report on rocks from West Antarctita and the Scotia Arc. Discovery Reports, 23:37-102

Wilcox R.E. 1954. Petrology of Paracutin Volcano, Mexico. US Geol. Surv: Bull. 965 C: $182 p$.

Wilson M. 1989. Igneous Petrogenesis. Unwin Hyman, London, 466p.

Zheng X., Liu X., Yang R. 1988. The petrological characteristics of Tertiary volcanic rocks near the Chinese Great Wall Station, West Antarctica. Acta Petrologica Sinica, 1:3447.

Manuscrito A-1195

Recebido $\mathrm{cm} 02$ de dezembro de 2000

Revisão dos autores $\mathrm{em} 03$ de julho de 2001 Revisão accita em 10 de julho de 2001 